\title{
Reinforcing effect of carboxymethylated nanofibrillated cellulose powder on hydroxypropyl cellulose
}

\author{
Ch. Eyholzer $\cdot$ F. Lopez-Suevos $\cdot$ P. Tingaut $\cdot$ \\ T. Zimmermann $\cdot$ K. Oksman
}

Received: 8 March 2010/ Accepted: 26 April 2010/Published online: 8 May 2010

(C) Springer Science+Business Media B.V. 2010

\begin{abstract}
Bionanocomposites of hydroxypropyl cellulose (HPC) and nanofibrillated cellulose (NFC) were prepared by solution casting. The various NFC were in form of powders and were prepared from refined, bleached beech pulp (RBP) by mechanical disintegration, optionally combined with a pre- or post mechanical carboxymethylation. Dynamic mechanical analysis (DMA) and tensile tests were performed to compare the reinforcing effects of the NFC powders to those of their never-dried analogues. For unmodified NFC powders an inferior reinforcing potential in HPC was observed that was ascribed to severe hornification and reagglomeration of NFC. In contrast, the composites with carboxymethylated NFC showed similar behaviors, regardless of the NFC suspensions being dried or not prior to composite preparation. SEM characterization confirmed a homogeneous dispersion
\end{abstract}

Ch. Eyholzer $(\bowtie) \cdot$ F. Lopez-Suevos ·

P. Tingaut - T. Zimmermann

Swiss Federal Laboratories for Materials Science and Technology (Empa), Dübendorf, Switzerland e-mail: christian.eyholzer@empa.ch

Ch. Eyholzer · K. Oksman

Division of Manufacturing and Design of Wood and Bionanocomposites, Luleå University of Technology (LTU), Luleå, Sweden

F. Lopez-Suevos

Centro de Innovación e Servizos Tecnolóxicos da Madeira de Galicia, CIS-Madeira, Parque Tecnolóxico de Galicia, Galicia, Spain of dried, carboxymethylated NFC within the HPC matrix. These results clearly demonstrate that drying of carboxymethylated NFC to a powder does not decrease its reinforcing potential in (bio)nanocomposites.

Keywords Nanofibrillated cellulose . Hydroxypropyl cellulose - Hornification .

Nanocomposites · Morphology ·

Dynamic mechanical properties .

Mechanical properties

\section{Introduction}

The general awareness of the increasing need for environmentally benign materials in building and construction, automotive and packaging at low cost has promoted a drastic increase in the research activities towards composites based on renewable and sustainable plant fibers (Hubbe et al. 2008). Among all biopolymers, cellulose is the most abundant and combines high strength and stiffness with low density and biodegradability (Zadorecki and Michell 1989; Couderc et al. 2009). Its inherent mechanical properties arise from $\beta-1,4$ linked glucopyranose chains, aligned into highly ordered (crystalline) domains by intra- and intermolecular hydrogen bonds. These crystallites are linked by amorphous domains to form bundles of fibrils (Azizi Samir et al. 2005). 
Successful isolation of cellulose fibrils with diameters below $100 \mathrm{~nm}$ is usually done by applying high shear forces to an aqueous suspension of never-dried cellulose pulp (Turbak et al. 1983; Herrick et al. 1983; Wågberg et al. 1987; Yano and Nakahara 2004; Zimmermann et al. 2004; Jonoobi et al. 2009). In order to enhance disintegration rate and lower energy consumption, chemical (Wågberg et al. 1987; Saito et al. 2006) and enzymatic (Pääkkö et al. 2007) pretreatments were applied. However, the yielded suspensions of nanofibrillated cellulose contain large amounts of water. Therefore, they suffer from bacterial degradation, require large storage facilities and generate high transportation costs. These ramifications could be avoided by preparing nanofibrillated cellulose (NFC) in powder form. However, simple drying of cellulose pulp from an aqueous suspension leads to irreversible agglomeration of the fibrils, called hornification (Scallan and Tigerström 1992; Laivins and Scallan 1993; Young 1994; Hult et al. 2001). This problem can be solved by functionalization of cellulose hydroxyl groups with carboxymethyl groups in their sodium form (Lindström and Carlsson 1982; Laivins and Scallan 1993). Following this approach, we recently reported the preparation and characterization of water-redispersible, chemically modified NFC powders (Eyholzer et al. 2010). The high interest in producing NFC in powder form for industrial application is reflected by several patents (Herrick 1984; Bahia 1995; Dinand et al. 1996; Excoffier et al. 1999; Cantiani et al. 2001; Cash et al. 2003; Bordeanu et al. 2008).

Nevertheless, the NFC starting material for mechanical reinforcement of polymer matrices is still predominantly used in form of never-dried aqueous suspensions. Several studies showed its high reinforcing potential on hydrophilic matrices like plasticized starch (Dufresne and Vignon 1998), poly(styrene-cobutyl acrylate) and poly(vinyl acetate) latexes (Azizi Samir et al. 2004; Dalmas et al. 2007; Lopez-Suevos et al. 2010), poly(vinyl alcohol) (Alemdar et al. 2009), polyurethane (Seydibeyoğlu and Oksman 2008), phenol-formaldehyde resin (Nakagaito and Yano 2005) and hydroxypropyl cellulose (Zimmermann et al. 2004). As compared to the neat matrices, these NFC composites essentially showed increased thermal stability, tensile strength and/or Young's Modulus. However, the preparation of composites containing water-redispersed NFC in powder form without the drawbacks of hornification has not been reported so far.

In this article, we present the elaboration and characterization of composites containing waterredispersed NFC powders and hydroxypropyl cellulose (HPC). This highly interesting cellulose derivative has been extensively analyzed regarding its ability to form liquid crystalline (LC) mesophases (Werbowyj and Gray 1976; Werbowyi and Gray 1980; Shimamura et al. 1981; Suto et al. 1982, 1986; Charlet and Gray 1987) and displays high compatibility with cellulosic nanofibers (Zimmermann et al. 2004; Johnson et al. 2009).

The aim of this work was to examine the effect of drying conventional and carboxymethylated NFC on their reinforcing potentials in HPC composites and further understand the interaction between the different phases. The composite films were characterized by dynamic mechanical analysis (DMA) and tensile testing and the results were compared to those from HPC composites containing the never-dried NFC counter-parts. Moreover, morphological characterization was done using scanning electron microscopy (SEM) to highlight the interactions at the fiber-matrix interface and confirm the interpretation of dynamic mechanical and tensile properties.

\section{Materials and methods}

Hydroxypropyl cellulose (HPC) with a molecular substitution (MS) of 3.4-4.4 and a weight-average molecular weight $\left(M_{\mathrm{w}}\right)$ of 100,000 was purchased from Sigma-Aldrich Chemie $\mathrm{GmbH}$ (Steinheim, Germany). The preparation of the various NFC powders is described elsewhere (Eyholzer et al. 2010). Briefly, refined bleached beech pulp (RBP) was carboxymethylated (c) and mechanically disintegrated using a high-shear laboratory homogenizer. In addition to RBP (untreated raw material), three NFC products were obtained by changing the sequence of the treatments (Fig. 1): NFC (mechanically isolated from RBP) and c-NFC and NFC-c (NFC that was carboxymethylated before and after mechanical disintegration, respectively), each yielded in the form of never-dried aqueous suspension and dry powder (after solvent exchange to isopropanol/ ethanol 5:3 w/w and oven drying at $60{ }^{\circ} \mathrm{C}$ under repeated stirring). 


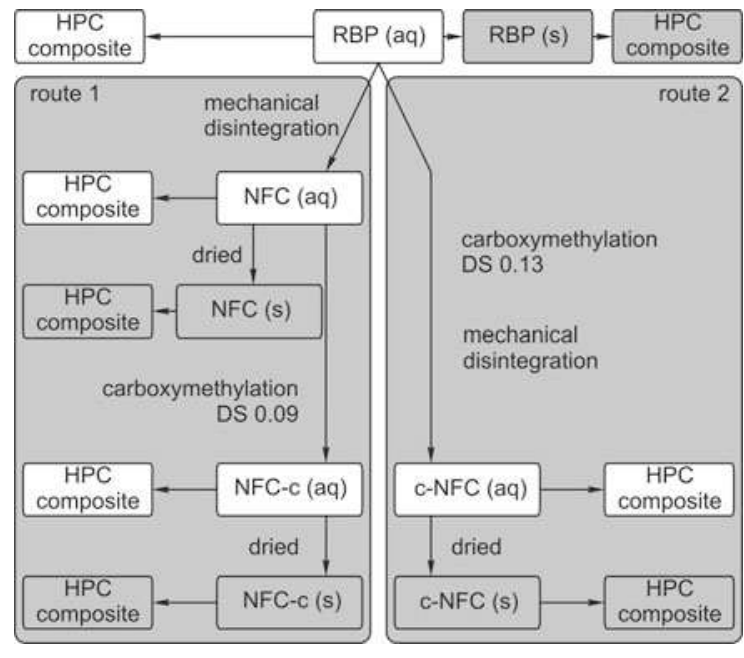

Fig. 1 Schematic overview on the sample preparation routes. In route 1 (left block), RBP was mechanically disintegrated (NFC), followed by carboxymethylation (NFC-c). In route 2 (right block), the treatments were interchanged and RBP was first carboxymethylated, followed by a mechanical disintegration step (c-NFC). White rectangles denote never-dried NFC products (aq) and composites prepared thereof. Shaded rectangles denote NFC products dried to a powder (s) and composites prepared thereof

\section{Preparation of composite films}

Composite films with fibril loadings of 5, 10 and 20\% $\mathrm{w} / \mathrm{w}$ were prepared at room temperature by mixing appropriate volumes of a $2.0 \% \mathrm{w} / \mathrm{w}$ aqueous solution of HPC with a $2.0 \% \mathrm{w} / \mathrm{w}$ aqueous suspension of the various RBP and NFC products, using a blender ( $T$ 25 basic, IKA-Werke, Staufen, Germany). Samples in powder form were redispersed in deionized water to yield a $2.0 \% \mathrm{w} / \mathrm{w}$ aqueous suspension, prior to mixing. The suspensions were then degassed under vacuum, cast in silicon moulds and placed in a laboratory hood. The films were left to dry for several days and showed thicknesses between 40 and $150 \mu \mathrm{m}$.

Dynamic mechanical analysis

The viscoelastic properties of the prepared films were studied by using a RS IIIa Rheometrics System Analyzer (TA Instruments, Delaware, USA) in tension mode. The composite films were cut into rectangular specimens with $6.0 \mathrm{~mm}$ width and $45.0 \mathrm{~mm}$ length and dried by storage over silica gel under vacuum for at least 3 days.
As HPC is very difficult to dry (Pizzoli et al. 1991), possibly remaining water on the samples was removed by heating to $180{ }^{\circ} \mathrm{C}\left(140{ }^{\circ} \mathrm{C}\right.$ for neat $\mathrm{HPC}$ samples and $150{ }^{\circ} \mathrm{C}$ for samples containing $5 \%$ of RBP, NFC or NFC-c) at a heating rate of $4{ }^{\circ} \mathrm{C} / \mathrm{min}$ and hold there for $2 \mathrm{~min}$ for equilibration. Dynamic cooling scans were performed from $180{ }^{\circ} \mathrm{C}$ (140 and $150{ }^{\circ} \mathrm{C}$, respectively) to $-30{ }^{\circ} \mathrm{C}$ at a cooling rate of $2{ }^{\circ} \mathrm{C} / \mathrm{min}$ and a frequency of $1 \mathrm{~Hz}$. The purge gas was dry air between 180 and $35^{\circ} \mathrm{C}$ and gas nitrogen below $35^{\circ} \mathrm{C}$. Initial load strain and initial static force were set to $0.09 \%$ and $2.0 \mathrm{~g}$, respectively. The static force was set $15 \%$ higher than the dynamic force. The upper limit for the applied load strain was set to $0.3 \%$. Three scans were averaged for each sample. The standard deviation in the DMA results (Figs. 2 and 3) shows the good reproducibility of the measurements for the three specimens of one sample.

\section{Tensile testing}

Modulus of elasticity (MOE), nominal tensile strength $\left(\sigma_{\max }\right)$ and tensile strain at break $(\varepsilon)$ were determined according to EN ISO 527-1:1996 with slight modifications. A Universal Testing System (Zwick 1474, Ulm, Germany), equipped with a $1 \mathrm{kN}$ load cell was used. Small dog-bone-shaped specimens were cut from the composite films using a clicker press. The specimens had an overall length of $75.0 \mathrm{~mm}$, a width of $12.0 \mathrm{~mm}$ at the clamping zone and a width of $4.0 \mathrm{~mm}$ at the stretching zone. The samples were conditioned for at least 1 week at $35 \%$ relative humidity and $20{ }^{\circ} \mathrm{C}$. Elongation of the samples was measured by optical strain detection. MOE values were determined by the slope of the linear interpolation line of the curves between 0.1 and $0.3 \%$ strain. The initial cross head speed was set to $0.5 \mathrm{~mm} / \mathrm{min}$ and increased to $5 \mathrm{~mm} / \mathrm{min}$ after the determination of the MOE to minimize creeping of the samples. For each sample, six replicates were measured. Of all 150 specimens measured, six replicates were rejected due to failure of the specimen within the grips or error in test procedure.

\section{SEM characterization}

The composite films were freeze-fractured in liquid nitrogen and the surfaces were sputtered with a $7.0 \mathrm{~nm}$ platinum coating. The samples were observed 
Fig. 2 Viscoelastic response of HPC films reinforced with a untreated RBP, b NFC, $\mathbf{c}$ NFC-c and d c-NFC. As a reference, $\mathrm{E}^{\prime}$ and tan delta of neat HPC films are included in all graphs (a)
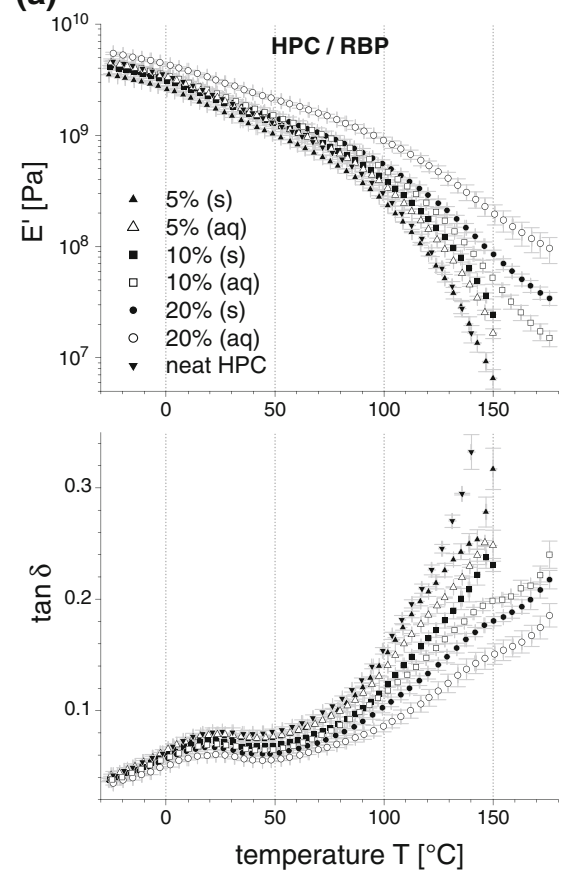

(c)

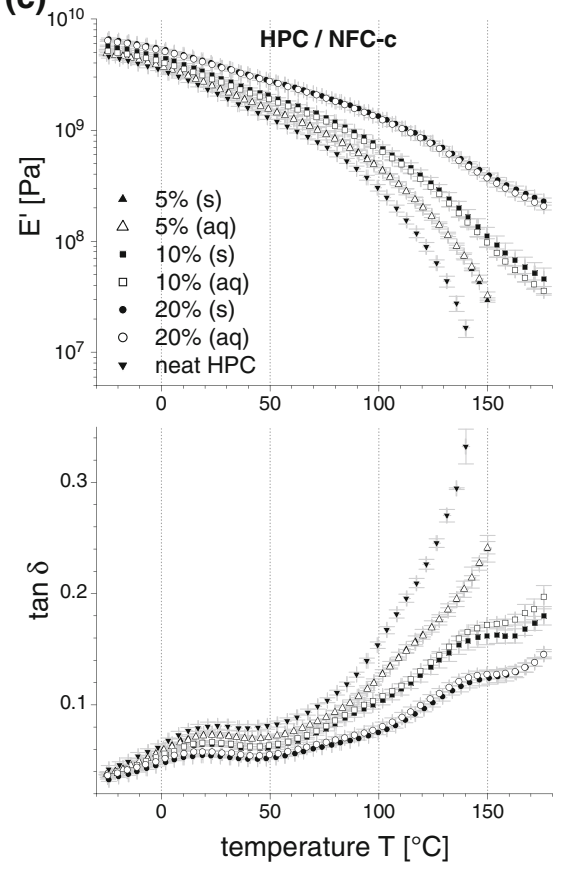

(b)
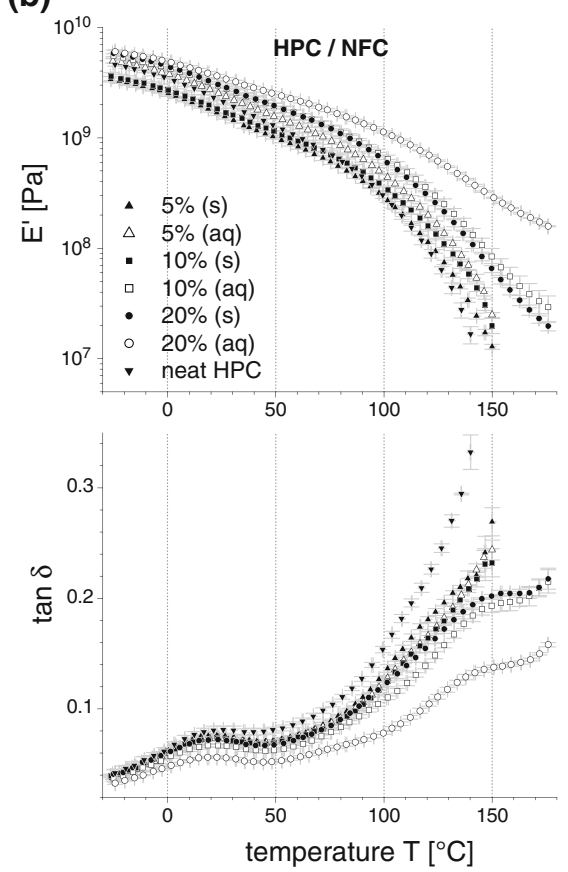

(d)
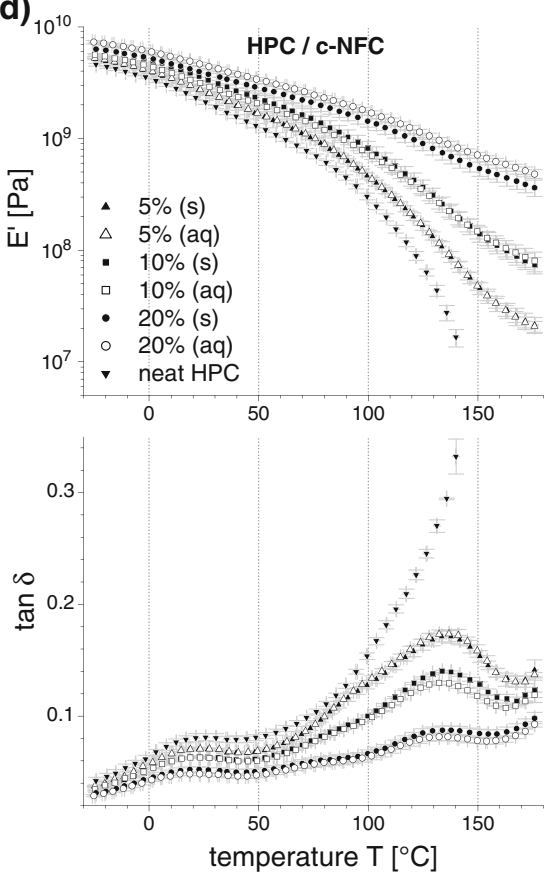

at an acceleration voltage of $5.0 \mathrm{kV}$ and a working distance of $5 \mathrm{~mm}$. Images were recorded in a FEI NovaNanoSEM 230 (FEI Company, Hillsboro, Oregon, USA) equipped with a Schottky field emission gun.

\section{Results and discussion}

The viscoelastic responses of all composites studied in this work are presented in Fig. 2 (with storage modulus $\mathrm{E}^{\prime}$ on top and $\tan \delta$ below). Figure 2a shows 
the viscoelastic response of HPC composite films reinforced with RBP. Figure $2 b$ and $c$ presents the viscoelastic response of HPC nanocomposites from route 1, containing mechanically isolated NFC and NFC that was further treated by carboxymethylation (NFC-c), respectively. Finally, Fig. $2 d$ shows the viscoelastic response of HPC nanocomposites from route 2, containing NFC that was carboxymethylated prior to mechanical disintegration (c-NFC). Fiber loadings are marked with triangles $(5 \% \mathrm{w} / \mathrm{w})$, rectangles $(10 \% \mathrm{w} / \mathrm{w})$ and circles $(20 \% \mathrm{w} / \mathrm{w})$. Samples containing dried and never-dried NFC products are denoted with filled and open symbols, respectively. In all DMA graphs, the viscoelastic response of neat HPC films is included as a reference (inverted triangles). All graphs show the same temperature, storage modulus and $\tan \delta$ scales in order to facilitate comparisons between nanocomposites. Also, the reproducibility of the viscoelastic response was very good, as demonstrated by the nearly perfect overlap of three repeat curves for each sample type.

\section{Viscoelastic properties of neat HPC}

The neat HPC films in Fig. 2a (inverted triangles) show three regions that are separated by two relaxations, $\alpha_{\mathrm{a}}$ and $\alpha_{\mathrm{m}}$, both involving large-scale molecular motion.

In the first region, ranging from -30 to $20{ }^{\circ} \mathrm{C}$ the films exhibit a very high storage modulus which is in the range of several GPa (Pizzoli et al. 1991). At these temperatures, the bulk HPC consists of essentially three distinct phases: a crystalline phase, a disordered isotropic amorphous phase and a phase of intermediate order which was described as a frozen anisotropic amorphous phase (Rials and Glasser 1988; Pizzoli et al. 1991; Wojciechowski 2000). At $20{ }^{\circ} \mathrm{C}$ a first transition can be observed, indicated by the peak in the $\tan \delta$ curve. This $\mathrm{T}_{\mathrm{g}}$-like transition (Aspler and Gray 1982; Rials and Glasser 1988) was attributed to the $\alpha_{\mathrm{a}}$ relaxation, denoting a devitrification process of the disordered amorphous phase (Pizzoli et al. 1991; Wojciechowski 2000).

The second region between 20 and $130{ }^{\circ} \mathrm{C}$ is characterized by a relatively large drop in storage modulus, exhibiting a remarkable softening of the films. Around $130{ }^{\circ} \mathrm{C}$ a second $\mathrm{T}_{\mathrm{g}}$-like transition occurs with a strong increase in the $\tan \delta$ intensity, known as the $\alpha_{\mathrm{m}}$ relaxation (Pizzoli et al. 1991). This relaxation was explained as the transition from the frozen anisotropic phase to a mobile liquid crystal thermotropic mesophase (Pizzoli et al. 1991; Wojciechowski 2000).

In the third region above $130{ }^{\circ} \mathrm{C}$, the storage modulus decreases drastically and the neat HPC films start to flow (Horio et al. 1988). At these temperatures, the flexible side chains of HPC act like an internal plasticizer, allowing the rather stiff main chains some mobility (Gray 1983). Due to this mobility, the main chains can orientate into a cholesteric conformation, stabilized by the side chains. Therefore, the molecular interactions of these side chains have a significant influence on the liquid crystal organization (Wojciechowski 2000). To avoid plastic deformation of the neat HPC films in tensile geometry, we limited data acquisition to $140{ }^{\circ} \mathrm{C}$ for this sample.

Viscoelastic properties of composites reinforced with never-dried (aq) NFC

To allow easier comparison, Fig. 3 shows the storage modulus values of the neat HPC films and composites with RBP and NFC products organized in columns at three arbitrary temperatures, i.e. at $-20{ }^{\circ} \mathrm{C}$ (below the $\alpha_{\mathrm{a}}$ relaxation; Fig. 3a), at $75{ }^{\circ} \mathrm{C}$ (between the $\alpha_{\mathrm{a}}$ and $\alpha_{\mathrm{m}}$ relaxations; Fig. $3 \mathrm{~b}$ ) and at $140{ }^{\circ} \mathrm{C}$ (above the $\alpha_{\mathrm{m}}$ relaxation; Fig. 3c). White and dark columns denote composites containing never-dried and driedredispersed cellulosic fillers, respectively.

As can be seen from the three diagrams, the storage modulus of the composite films increased with fiber loadings regardless of the treatment. Below the $\alpha_{\mathrm{a}}$ relaxation at $-20{ }^{\circ} \mathrm{C}$, the increase in storage modulus was generally small (Fig. 3a). At $75^{\circ} \mathrm{C}$, after the $\alpha_{\mathrm{a}}$ relaxation (Fig. $3 \mathrm{~b}$ ) this increase becomes more pronounced, but the strongest increase in storage modulus with higher fiber loadings compared to neat HPC was observed at $140{ }^{\circ} \mathrm{C}$, after the $\alpha_{\mathrm{m}}$ relaxation (Fig. 3c). This later increase in storage modulus was associated with the formation of a highly rigid percolating network of fibrils (Dalmas et al. 2007). The rigidity of this network arises from strong hydrogen bonds and entanglements between the fibrils.

Clearly, the $\tan \delta$ intensity of all composites was reduced with higher filler content over the whole temperature range but most pronounced in the high 
(a)

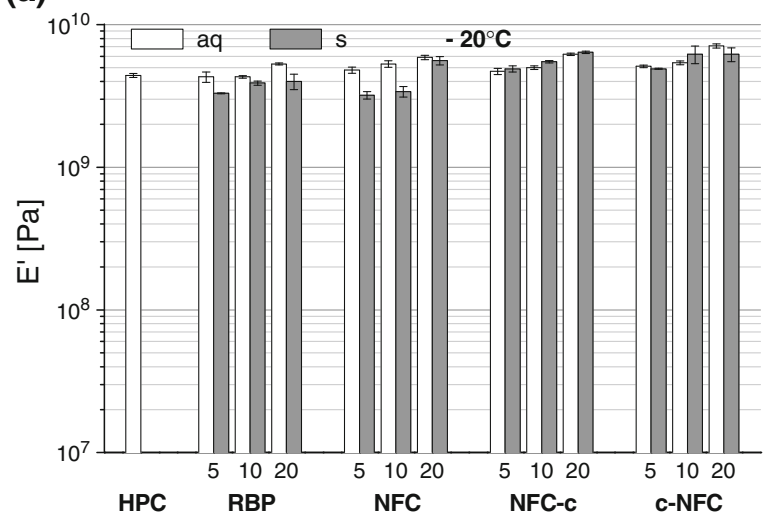

(c)



Fig. 3 Storage moduli of HPC films reinforced with RBP and NFC products at temperatures of a $-20{ }^{\circ} \mathrm{C}, \mathbf{b} 75^{\circ} \mathrm{C}$ and c $140{ }^{\circ} \mathrm{C}$. White columns denote films reinforced with never

temperature region above $130{ }^{\circ} \mathrm{C}$ (Fig. 2). This decrease in $\tan \delta$ can (partly) be explained with the increased volume fraction of the filler in the composites. However, when comparing composites with equal loadings of filler it can be observed that the decrease in $\tan \delta$ intensity depends on the filler type, becoming more pronounced in the following order: RPB $<$ NFC $<$ NFC-c $<$ c-NFC (Fig. 2). This suggests that the presence of the fillers (and the percolating networks they form) promoted different degrees of segmental restrictions of the molecular motion of HPC chains, leading to an increase in $\mathrm{E}^{\prime}$ and a decrease in $\tan \delta$. The efficiency of these segmental restrictions may depend on surface chemistry (i.e. the availability of carboxylate groups $\mathrm{COO}^{-}$), surface area to volume ratio and aspect ratio of the filler (Johnson et al. 2009). (b)

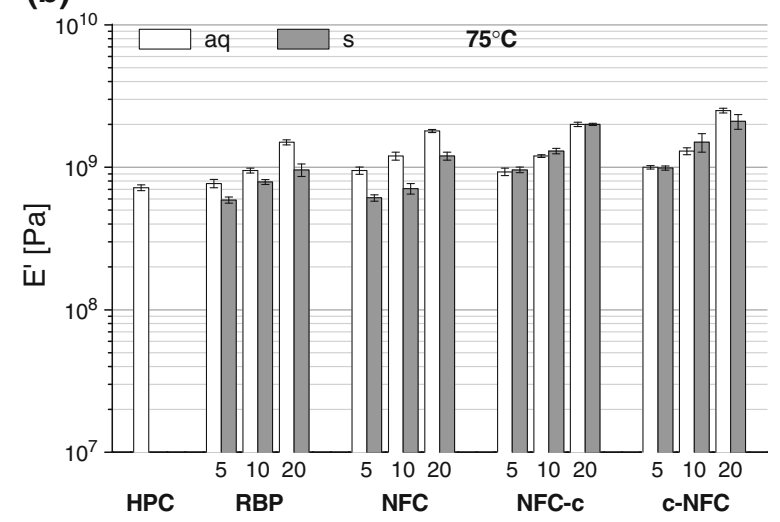

dried NFC products. Dark columns denote films reinforced with NFC products dried to a powder before compounding

It was earlier reported that carboxymethylation prior to mechanical disintegration (c-NFC) enhances the isolation of fibrils (Wågberg et al. 2008; Eyholzer et al. 2010). This might lead to the production of fibrils which are favorable in terms of the above mentioned properties compared to chemically unmodified NFC or RBP and therefore account for more efficient segmental restriction of HPC molecular motion.

Viscoelastic properties of composites reinforced with dried (s) NFC

Similarly to the composites containing the neverdried cellulosic fillers discussed above, an increase in $\mathrm{E}^{\prime}$ with the filler loading was observed for the composites reinforced with dried RBP and NFC, 
regardless of the treatment (Fig. 3a, b and c). However, a clear difference was observed between the films containing carboxymethylated (NFC-c and c-NFC) and those containing chemically unmodified fibers (RBP and NFC). For all temperatures studied, storage modulus values of samples containing redispersed RBP and NFC were clearly lower than those of their never-dried analogues. This effect can be attributed to the hornification of RBP and NFC fibrils upon drying (Eyholzer et al. 2010), leading to a reduction of the fiber's aspect ratio and the prevention of a percolating network formation.

In contrast, films containing the dried NFC products that were carboxymethylated (NFC-c and c-NFC), showed an almost identical response as those containing the never-dried fibers in the whole temperature range (Fig. 3a, b and c). These results prove that carboxymethylated NFC can be dried and redispersed in water without affecting its mechanical performance in a nanocomposite. To confirm this suggestion, tensile tests were performed with specimens obtained from the same composite films.

\section{Tensile tests}

Figure 4a shows the nominal modulus of elasticity (MOE) of neat HPC and the composites containing RBP and NFC products in dried and never-dried condition. Once again, an increase in MOE with higher fiber loadings was measured for the films containing never-dried NFC products with a maximum increase for films containing $20 \% \mathrm{w} / \mathrm{w}$ of cNFC (of up to approximately three times compared to neat HPC films).

In agreement with the data obtained from DMA, drying of carboxymethylated NFC products (NFC-c and c-NFC) did not lead to a significant reduction of the reinforcing effect, in contrast to unmodified RBP and NFC. Interestingly, films with dried NFC showed decreasing MOE values with higher loadings. Once again, this behavior was associated with an extensive hornification of the mechanically disintegrated fibrils, leading to films with poor homogeneity. The same trends were observed when analyzing the nominal strength values $\left(\sigma_{\max }\right)$ of the composites (Fig. $4 b$ ). Composites containing dried carboxymethylated NFC products (NFC-c and c-NFC) showed similar $\sigma_{\max }$ values as composites reinforced with neverdried fibers, displaying almost 3 times higher values than neat HPC. The displayed reinforcement is in the same range as observed for composites of HPC and never-dried NFC in an earlier publication (Zimmermann et al. 2004).

Figure $4 \mathrm{c}$ shows the strain to break values of neat HPC and the composites containing RBP and NFC products in dried and never-dried condition. Neat HPC films showed a strain to break around $20 \%$ with a relatively large standard deviation that might originate from the susceptibility of HPC towards moisture (Pizzoli et al. 1991). A clear decrease of $\varepsilon$ was found for all composites containing chemically modified fibers (NFC-c and c-NFC), regardless of being compounded in dried or never-dried condition. This can be attributed to the rigidity of the incorporated fibrils. In agreement with the DMA results, the tensile measurements therefore confirm that carboxymethylated NFC products show the same reinforcing effect in a HPC matrix, regardless of compounded in dried or never-dried condition.

\section{Characterization by SEM}

Figure 5 shows SEM images of freeze-fractured surfaces of a neat HPC film (Fig. 5a) and composite films containing $20 \% \mathrm{w} / \mathrm{w}$ of dried NFC (Fig. $5 \mathrm{~b}$ ) and $20 \%$ w/w of dried c-NFC (Fig. 5c). Neat HPC showed grain sizes in the micrometer range, as already reported in the literature (Johnson et al. 2009). The composite film containing dried NFC (Fig. 5b) showed voids and large aggregations of fibrils (indicated by arrows), confirming the poor dispersion and the hornification of NFC in the matrix. In contrast, the surface morphology of composite films containing dried c-NFC was dominated by the coherent structure of the fibrils. Their orientation may suggest that the fibrils were deposited in a layered structure during the slow evaporation of water in the solution casting process. The uniform structure may origin from a homogeneous dispersion of the fibrils in the HPC matrix.

\section{Conclusions}

Bionanocomposites from hydroxypropyl cellulose (HPC) with dried and redispersed nanofibrillated cellulose (NFC) powders were prepared by solution casting from water. The various NFC powders were obtained by solely mechanical disintegration (NFC) 

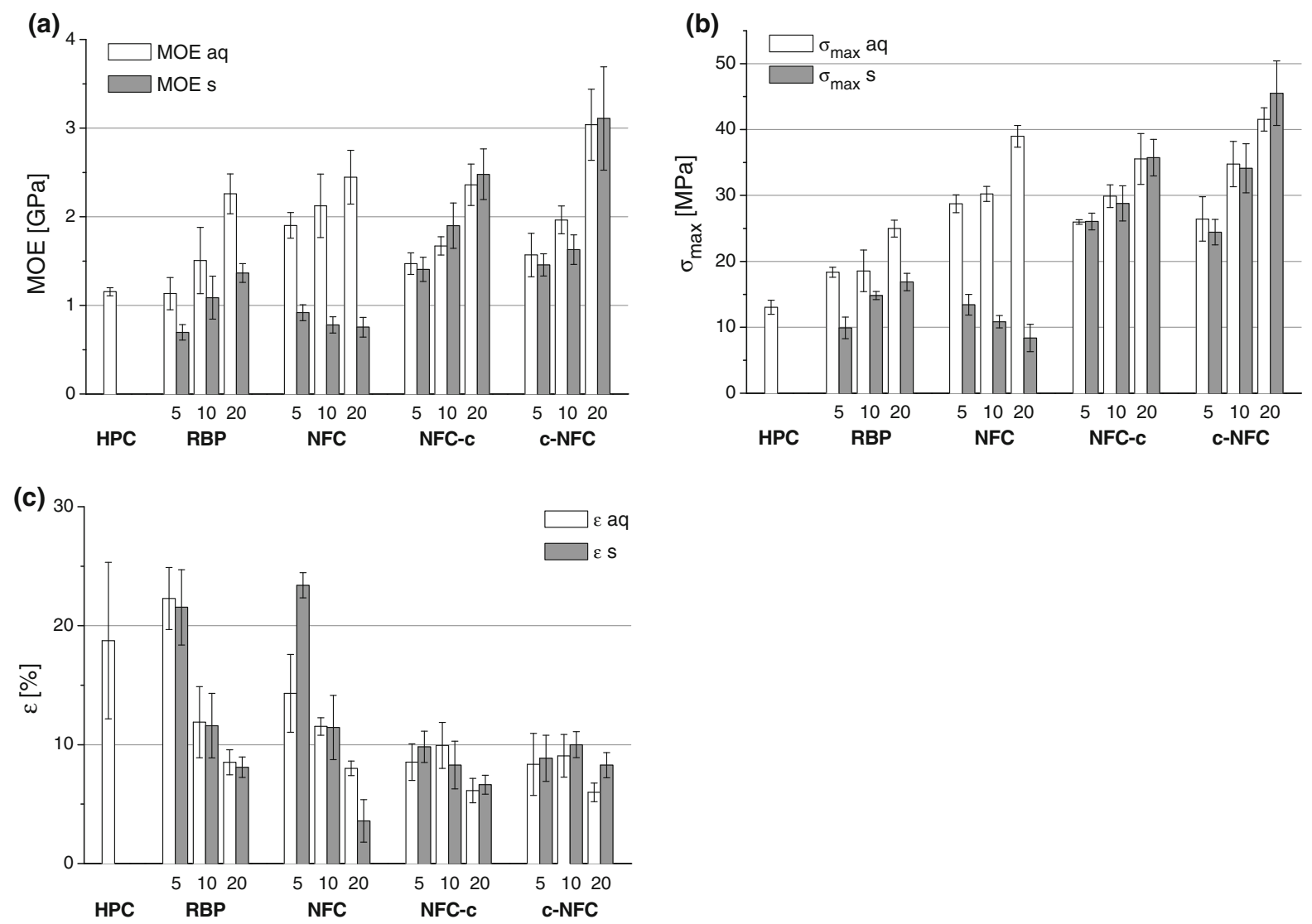

Fig. 4 a Modulus of elasticity, b ultimate strength and c elongation to break values of HPC films reinforced with $\mathrm{RBP}$ and NFC products at room temperature, obtained from

tensile tests. Open columns denote films reinforced with never dried NFC products. Filled columns denote films reinforced with NFC products dried to a powder before compounding

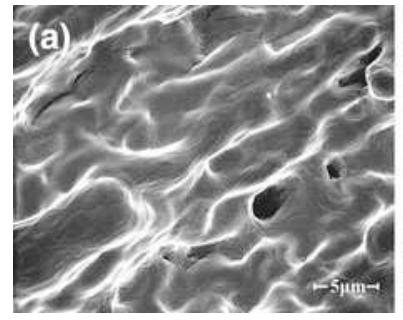

Fig. 5 SEM images of freeze-fractured surfaces from a neat HPC film, b composite film of HPC, reinforced with $20 \%$ w/w of dried and redispersed NFC and composite film of HPC,

or in combination with pre- or post mechanical carboxymethylation (c-NFC and NFC-c) of refined, bleached beech pulp (RBP). The mechanical and morphological properties of the composites were analyzed by DMA, tensile tests and SEM imaging and compared to those from composites prepared with the same RBP products that were never dried. reinforced with $20 \% \mathrm{w} / \mathrm{w}$ of dried and redispersed c-NFC. All images are magnified $10,000 \times$

DMA analysis and tensile tests showed that the highest reinforcing effect was observed for films containing c-NFC, in terms of storage modulus $\left(\mathrm{E}^{\prime}\right)$, modulus of elasticity (MOE) and nominal tensile strength $\left(\sigma_{\max }\right)$. Enhanced isolation of the fibrils may account for the higher performance compared to the films containing the chemically unmodified RBP and 
NFC fibers. In general, the mechanical response of carboxymethylated NFC products in the composites was independent of whether the fibrils were dried or not prior to compounding. NFC without carboxylate groups showed a strong decrease of its reinforcing potential when dried before mixing with HPC due to hornification. Consistently, SEM characterization of a freeze-fractured HPC film containing dried c-NFC showed a continuous and homogeneously dispersed structure.

These results demonstrate that carboxymethylated NFC preserves its mechanical reinforcing potential when dried to a powder and redispersed in water. Therefore, carboxymethylated and mechanically isolated NFC in powder form has a high potential for polymer reinforcement with increased shelf life and easier handling compared to conventional NFC aqueous suspensions.

Acknowledgments The authors gratefully acknowledge the State Secretariat for Education and Research (SER) for financial support of this work.

\section{References}

Alemdar A, Osman K, Sain M (2009) The effect of decreased fiber size in wheat straw/polyvinyl alcohol composites. J Biobased Mat Bioenerg 3:75-80

Aspler JS, Gray DG (1982) Interaction of organic vapours with hydroxypropyl cellulose. Polymer 23:43-46

Azizi Samir MAS, Alloin F, Paillet M, Dufresne A (2004) Tangling effect in fibrillated cellulose reinforced nanocomposites. Macromolecules 37:4313-4316

Azizi Samir MAS, Alloin F, Dufresne A (2005) Review of recent research into cellulosic whiskers, their properties and their application in nanocomposite field. Biomacromolecules 6:612-626

Bahia HS (1995) Treatment of cellulose. Patent publication number WO9515342

Bordeanu N, Eyholzer Ch, Zimmermann T (2008) Cellulose nanostructures with tailored functionalities. Pending patent

Cantiani R, Guerin G, Senechal A, Vincent I, Benchimol J (2001) Patent publication numbers US6224663, US6231657, US6306207

Cash MJ, Chan AN, Conner HT, Cowan PJ, Gelman RA, Lusvardi KM, Thompson SA, Tise FP (2003) Derivatized microfibrillar polysaccharide. Patent publication number WO0047628

Charlet G, Gray DG (1987) Solid cholesteric films cast from aqueous (hydroxypropyl)cellulose. Macromolecules 20: $33-38$

Couderc S, Ducloux O, Kim BJ, Someya T (2009) A mechanical switch device made of a polyimide-coated microfibrillated cellulose sheet. J Micromech Microeng 19:055006

Dalmas F, Cavaillé JY, Gauthier C, Chazeau L, Dendievel R (2007) Viscoelastic behaviour and electrical properties of flexible nanofiber filled polymer nanocomposites. Influence of processing conditions. Comp Sci Technol 67: 829-839

Dinand E, Chanzy H, Vignon M, Maureaux A, Vincent I (1996) Microfibrillated cellulose and method for preparing same from primary wall plant pulp, particularly sugar beet pulp. Patent publication number WO9624720

Dufresne A, Vignon MR (1998) Improvement of starch film performances using cellulose microfibrils. Macromolecules 31:2693-2696

Excoffier G, Vignon M, Benchimol J, Vincent I, Hannuksela T, Chauve V (1999) Parenchyma cellulose substituted with carboxyalkyl groups and preparation method. Patent publication number WO9938892

Eyholzer Ch, Bordeanu N, Lopez-Suevos F, Rentsch D, Zimmermann T, Oksmann K (2010) Preparation and characterization of water-redispersible nanofibrillated cellulose in powder form. Cellulose 17:19-30

Gray DG (1983) Liquid crystalline cellulose derivatives. J Appl Polym Sci Appl Polym Symp 37:179-192

Herrick FW (1984) Process for preparing microfibrillated cellulose. Patent publication number US4481077

Herrick FW, Casebier RL, Hamilton JK, Sandberg KR (1983) Microfibrillated cellulose: morphology and accessibility. J Appl Polym Sci Appl Polym Symp 37:797-813

Horio M, Kamei E, Matsunobu K (1988) Dynamic measurements on polymer liquid crystals II. Thermotropic mesophase of hydroxypropyl cellulose. J Soc Rheol Jpn 16:2732

Hubbe MA, Rojas OJ, Lucia LA, Sain M (2008) Cellulosic nanocomposites: a review. Biores 3:929-980

Hult EL, Larsson PT, Iversen T (2001) Cellulose fibril aggregation-an inherent property of kraft pulps. Polymer 42:3309-3314

Johnson RK, Zink-Sharp A, Renneckar SC, Glasser WG (2009) A new bio-based nanocomposite: fibrillated TEMPOoxidized celluloses in hydroxypropylcellulose matrix. Cellulose 16:227-238

Jonoobi M, Harun J, Mathew A, Hussein M, Oksmann K (2009) Preparation of cellulose nanofibers with hydrophobic surface characteristics. Cellulose. doi: 10.1007/s10570-009-9387-9

Laivins GV, Scallan AM (1993) The mechanism of hornification of wood pulps. In: Proceedings of the 10th fundamental research symposium, Oxford, 1235-1260

Lindström T, Carlsson G (1982) The effect of carboxyl groups and their ionic form during drying on the hornification of cellulose fibers. Svensk Papperstidning 85:R146-R151

Lopez-Suevos F, Eyholzer Ch, Bordeanu N, Richter K (2010) DMA analysis and wood bonding of PVAc latex reinforced with cellulose nanofibrils. Cellulose 17:387-398

Nakagaito AN, Yano H (2005) Novel high-strength biocomposites based on microfibrillated cellulose having nanoorder-unit web-like network structure. Appl Phys A 80:155-159

Pääkkö M, Ankerfors M, Kosonen H, Nykänen A, Ahola S, Österberg M, Ruokolainen J, Laine J, Larsson PT, Ikkala 
O, Lindström T (2007) Enzymatic hydrolysis combined with mechanical shearing and high-pressure homogenization for nanoscale cellulose fibrils and strong gels. Biomacromolecules 8:1934-1941

Pizzoli M, Scandola M, Ceccorulli G (1991) Dielectrical and mechanical loss processes in hydroxypropylcellulose. Plast Rubber Comp Process Appl 16:239-244

Rials TG, Glasser WG (1988) Thermal and dynamic mechanical properties of hydroxypropyl cellulose films. J Appl Polym Sci 36:749-758

Saito T, Nishiyama Y, Putaux JL, Vignon M, Isogai A (2006) Homogeneous suspensions of individualized microfibrils from TEMPO-catalyzed oxidation of native cellulose. Biomacromolecules 7:1687-1691

Scallan AM, Tigerström AC (1992) Swelling and elasticity of the cell walls of pulp fibers. J Pulp Pap Sci 18:188-193

Seydibeyoğlu MO, Oksman K (2008) Novel nanocomposites based on polyurethane and micro fibrillated cellulose. Comp Sci Technol 68:908-914

Shimamura K, White JL, Fellers JF (1981) Hydroxypropylcellulose, a thermotropic liquid crystal: characteristics and structure development in continuous extrusion and melt spinning. J Appl Polym Sci 26:2165-2180

Suto S, White JL, Fellers JF (1982) A comparative study of the thermotropic mesomorphic tendencies and rheological characteristics of three cellulose derivatives: ethylene and propylene oxide esters and an acetate butyrate ester. Rheol Acta 21:62-71

Suto S, Kudo M, Karasawa M (1986) Static tensile and dynamic mechanical properties of hydroxypropylcellulose films prepared under various conditions. J Appl Polym Sci $31: 1327-1341$
Turbak AF, Snyder FW, Sandberg KR (1983) Microfibrillated cellulose, a new cellulose product: properties, uses, and commercial potential. J Appl Polym Sci Appl Polym Symp 37:815-823

Wågberg L, Winter L, Ödberg L, Lindström T (1987) On the charge stoichiometry upon adsorption of a cationic polyelectrolyte on cellulosic materials. Colloid Surf 27:163-173

Wågberg L, Decher G, Norgren M, Lindström T, Ankerfors M, Axns K (2008) The build-up of polyelectrolyte multilayers of microfibrillated cellulose and cationic polyelectrolytes. Langmuir 24:784-795

Werbowyi RS, Gray DG (1980) Ordered phase formation in concentrated hydroxypropylcellulose solutions. Macromolecules 13:69-73

Werbowyj RS, Gray DG (1976) Liquid crystalline structure in aqueous hydroxypropyl cellulose solutions. Mol Cryst Liq Cryst 34(Letters): 97-103

Wojciechowski P (2000) Thermotropic mesomorphism of selected (2-hydroxypropyl) cellulose derivatives. J Appl Polym Sci 76:837-844

Yano H, Nakahara S (2004) Bio-composites produced from plant microfiber bundles with a nanometer unit web-like network. J Mater Sci 39:1635-1638

Young RA (1994) Comparison of the properties of chemical cellulose pulps. Cellulose 1:107-130

Zadorecki P, Michell AJ (1989) Future-prospects for wood cellulose as reinforcement in organic polymer composites. Polym Compos 10:69-77

Zimmermann T, Pöhler E, Geiger T (2004) Cellulose fibrils for polymer reinforcement. Adv Eng Mater 6:754-761 